\begin{tabular}{|c|c|}
\hline $\begin{array}{l}\text { 2. To: (Receiving Organization) } \\
\text { Data Development and } \\
\text { Interpretation }\end{array}$ & $\begin{array}{l}\text { 3. From: (Originating Organization) } \\
\text { FH Technology, Operations and } \\
\text { Process Science }\end{array}$ \\
\hline 5. Proj./Prog./Dept./Div.: & $\begin{array}{l}\text { 6. Design Authority/ Design Agent/Cog. } \\
\text { Engr.: }\end{array}$ \\
\hline $\begin{array}{l}\text { WIT Solubility Tests/Waste } \\
\text { Management/TOPS/FH }\end{array}$ & J.C. Person \\
\hline
\end{tabular}

8. Originator Remarks:

This document is being released as a supporting document.

11. Receiver Remarks:

For release.
11A. Design Baseline Document?

[] Yes

$[X]$ No
4. Related EDT No.:

NA

7. Purchase Order No.:

NA

9. Equip./Component No.: NA

10. System/Bldg./Facility: 222-S Laboratory

12. Major Assm. Dwg. No.: NA

13. Permit/Permit Application No.: NA

14. Required Response Bate:

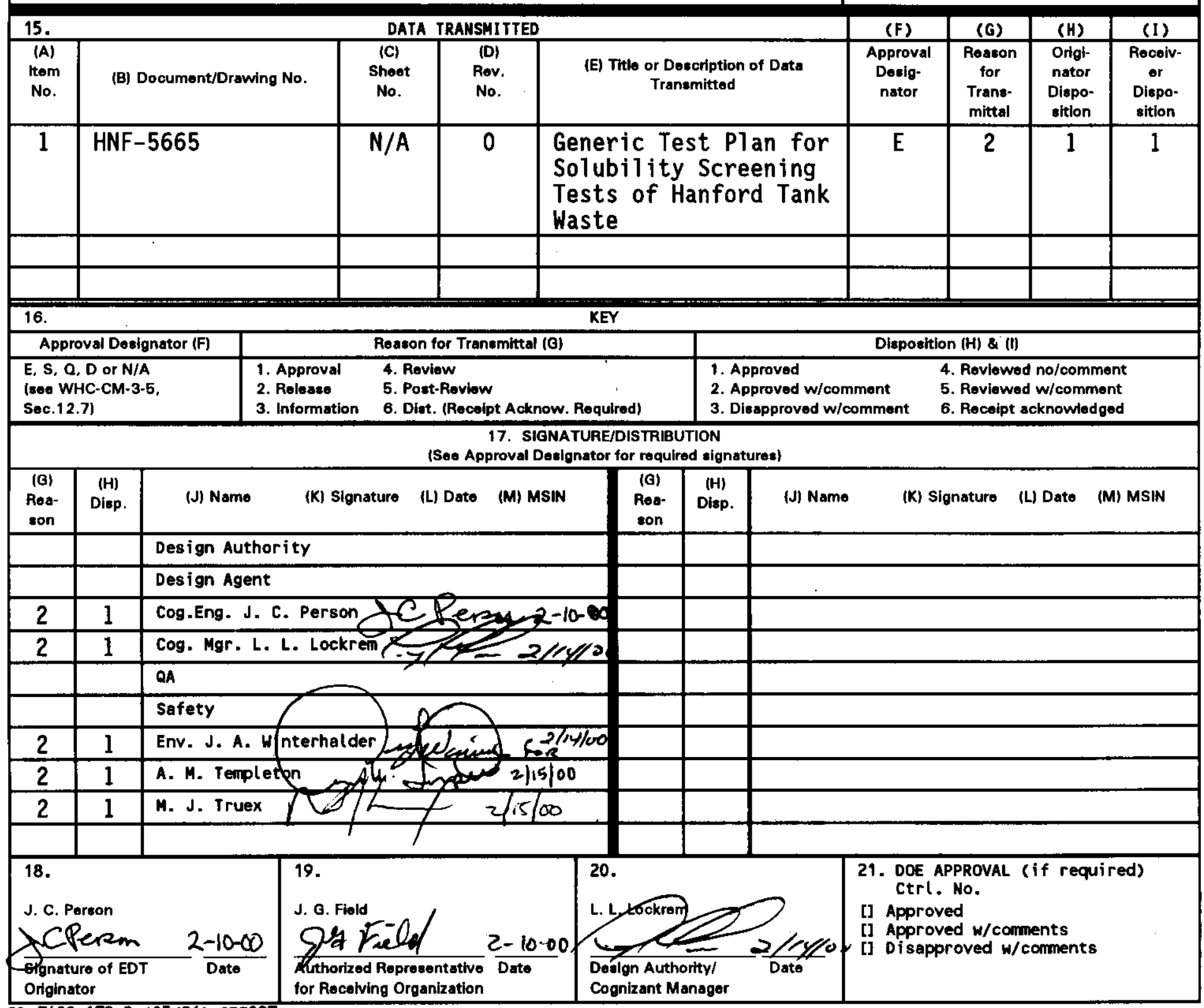




\title{
Generic Test Plan for Solubility Screening Tests of Hanford Tank Waste
}

\section{J. C. Person}

Fluor Hanford, Richland, WA 99352

U. S. Department of Energy Contract DE-AC06-96RL13200

\author{
EDT/ECN: $620370 \quad$ UC: 2070 \\ Org Code: 8D500 CACN/COA: 103430/AT00 \\ B\&R Code: EW 3120074 Total Pages: 22
}

Key Words: Solubility, Privatization, Sludge, Solids Composition

Abstract: Waste pretreatment and immobilization requires the tank waste to be retrieved. Retrieval from tanks may require dilution. This test determines the effects of dilution on the mass of solids and their composition. This test plan gives test instructions, example data sheets, a waste compatibility review, and a waste stream fact sheet.

TRADEMARK DISCLAIMER. Reference herein to any specific commercial product, process, or service by trade name, trademark, manufacturer, or otherwise, does not necessarily constitute or imply its endorsement, recommendation, or favoring by the United States Government or any agency thereof or its contractors or subcontractors.

Printed in the United States of Ameriça. To obtain copies of this document, contact: Document Control Services, P.O. BOx 950, Mailstop H6-08, Richland WA 99352, Phone (509) 372-2420; Fax (509) 376-4989.
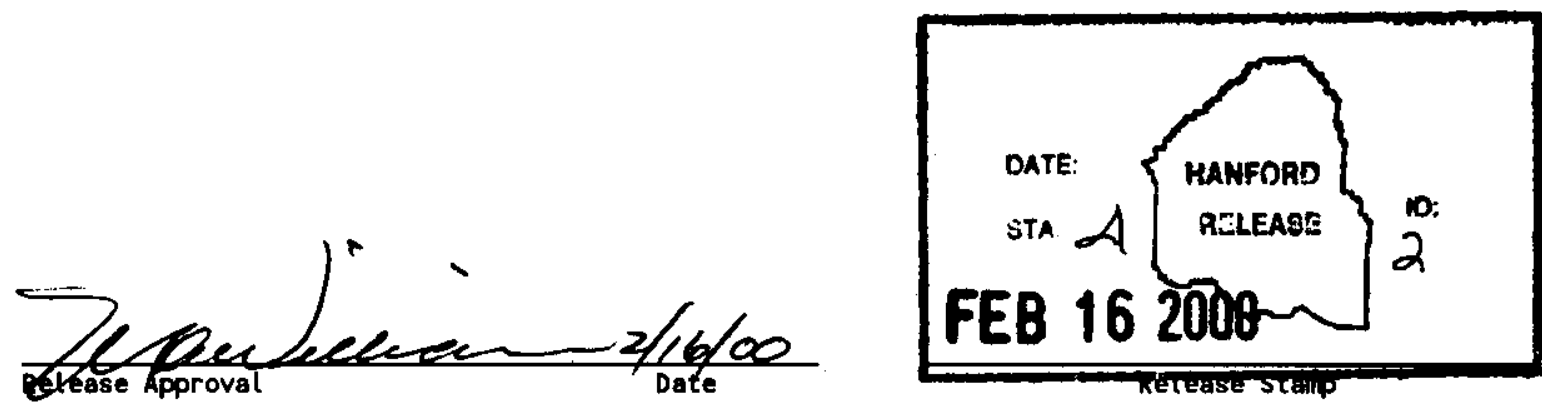

\section{Approved for Public Release}


HNF-5665, Rev. 0

CONTENTS

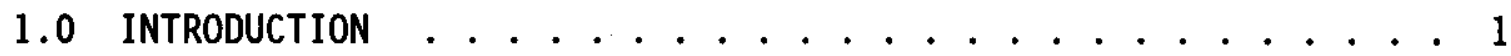

2.0 AMOUNT OF TEST MATERIAL NEEDED . . . . . . . . . . 1

2.1 Material Used for Tests . . . . . . . . . . . . . 1

2.2 Weights Needed for Solubility Screening Tests . . . . 2

3.0 DESCRIPTION OF TEST . . . . . . . . . . . . . . 5

3.1 Observations on Starting Material ........ 5

3.2 Centrifuged Solids (C-Sol) Preparation ....... 6

3.3 Solubility Screening Tests .......... 7

4.0 DATA INTERPRETATION ................. 9

4.1 Chemical Data ................. . . . . 9

4.2 Quality Assurance ............... 10

5.0 SAFETY ....................... 10

6.0 WASTE HANDLING ........................ 11

7.0 SCHEDULE AND DELIVERABLES ................. 11

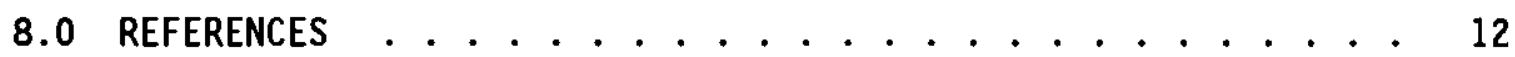

\section{APPENDICES}

A: EXAMPLE DATA SHEETS ................ . . . A-1

B： WASTE COMPATIBILITY REVIEW ............... B-1

C: WASTE StREAM FACT SHEET ............... . C-1 
HNF -5665 , Rev. 0

LIST OF TERMS

$\begin{array}{ll}\text { 101-AZ } & \text { Tank 241-AZ-101 } \\ \text { 102-AZ } & \text { Tank 24l-AZ-102 } \\ \text { AT } & \text { total alpha } \\ \text { C-S01 } & \text { centrifuged solids } \\ \text { Cm } & \text { centimeter } \\ \text { DQO } & \text { data quality objective } \\ \text { G } & \text { gravity } \\ \text { g } & \text { gram } \\ \text { ga1 } & \text { gallon } \\ \text { GEA } & \text { gamma energy analysis } \\ \text { IC } & \text { ion chromatography } \\ \text { ICP } & \text { inductively-coupled plasma } \\ \text { ISL } & \text { interstitial liquid } \\ \text { L } & \text { liter } \\ \text { mL. } & \text { polliliter } \\ \text { PCB } & \text { polarized light microscopy } \\ \text { PLM } & \text { Pacific Northwest National Laboratory } \\ \text { PNNL } & \text { quality assurance } \\ \text { QA } & \text { sampling and analysis plan } \\ \text { SAP } & \text { settled solids } \\ \text { S-SO1 } & \text { total inorganic carbon (C present as } \mathrm{CO}_{3}{ }^{2-} \text { ) } \\ \text { TIC } & \text { total organic carbon } \\ \text { TOC } & \text { volume percent } \\ \text { Vol\% } & \text { weight percent } \\ \text { Wt\% } & \end{array}$


HNF-5665, Rev. 0

\subsection{INTRODUCTION}

Waste pretreatment and immobilization requires the tank waste to be retrieved. Retrieval of the tank waste may require dilution. This test determines the effects of dilution on the mass of solids and their composition, effects that can be compared with other tanks. This test plan gives test instructions, example data sheets, a waste compatibility review, and a waste stream fact sheet.

The tests will be done on centrifuged solids separated from composite samples prepared to be representative of the contents of the tank. This document is designed as a generic plan for use with the Hanford waste tanks. Prototype Test PIans were prepared previously for tanks 241-AZ-102 (102-AZ, Person 1999b) and 241-AZ-101 (101-AZ, Person 1999c) in order to meet requirements of the prototype Sampling and Analys is Plans (SAP, Rasmussen 1999 for 102-AZ, and Templeton 1999b for 101-AZ). The solubility screening tests in this test plan satisfy some of the data quality objectives (DQO) specified for Low Activity Waste and High-Level Waste Feed Processing (Patella 1999). This test $\mathrm{plan}$ may be used for tanks where the SAP requires solubility tests according to the DQO (Patello 1999), provided this plan satisfies the SAP requirements.

\subsection{AMOUNT OF TEST MATERIAL NEEDED}

This document describes four solubility screening tests to be made at four different levels of dilution. Analyses of the solids and liquids present after dilution are used to estimate the amount of interstitial liquid (ISL) present in the wet solids and the wt\% of the different analytes in the ISL and in the dry (undissolved) solids. Test material is needed for the four solubility screening tests.

\subsection{Material Used for Tests}

The solubility screening tests are done on samples of the centrifuged solids (c-sol), which are then diluted by various amounts. This test plan assumes that 11A hotcell personnel prepare the starting material for this $\mathrm{plan}$ to be representative of the material in the core. This composite material can be prepared as a composite slurry (or as four composite slurries), with each slurry prepared by dividing the solids and the liquids from each segment among all of the composites being prepared. Alternatively, the solids from all segments can be combined into one solids composite and the liquids combined into a liquid composite. Portions of these composites are then used to make the slurry composites used for these tests. In either case, observations of the original samples would be made by $11 \mathrm{~A}$ hotcell personnel of (a) total sample weight and volume, (b) vol\% settled solids after a settling time greater than 16 hours, and (c) visual observations, including the presence or absence of floating layers (organics or solids) and any indications of gas generation within the sample. 
HNF-5665, Rev. 0

\subsection{Weights Needed for Solubility Screening Tests}

The estimated weight of solids required depends on several parameters. This subsection describes the parameters and equations used to estimate the amount of material needed, with an example estimation given at the end. The parameters used and the weights estimated include the following.

Parameters:

$W_{\text {lab }}$ Sample weight desired for submission to the laboratory for the analyses.

$f_{t v}$ Weight fraction transferred from a vial (where rinsing with supernate is allowed).

$f_{t c}$ Weight fraction transferred from a centrifuge cone (where rinsing is not allowed).

$W_{\text {loss }}$ Weight lost in transfer from a centrifuge cone. This includes any weight spilled or lost on a transfer tool (tool losses can be avoided for material that flows when vortexed).

$f_{i}$ Weight fraction of solids that remain undissolved after the ith Test dilution.

$r_{c / s}$ Weight ratio of c-sol to $s-s o l$ (settled solids).

Weights to Calculate:

$W_{c s, T i}$ Weight of c-sol needed to prepare the ith Test mixture, see Eq $(2-1)$.

$W_{c s, s m}$ Sum of weights of c-sol needed to prepare four Test mixtures, see Eq (2-2).

$W_{c s, s l}$ Weight of c-sol needed in slurry to yield $W_{c s, s m}$, see Eq (2-3).

$W_{s s, s l}^{c s}$ Weight of initial s-sol needed to produce a composite slurry that will yield $W_{c s, s 1}$, see Eq $(2-4)$.

Thus the c-sol weights use Eq (2-1) to calculate the $W_{c s}$.I terms for each Test. These terms are summed in Eq (2-2) to give $W_{c q s}{ }_{c s}$, the weight of c-sol needed in an initial slurry $\left(W_{c s, s l}\right)$ is shown in Eq $(29-3)$.

$$
\begin{aligned}
& W_{c s, T i}=\left(W_{\text {lab }}+W_{\text {loss }}\right) / f_{i} / f_{t c} / f_{t v} \\
& W_{c s, s m}=\Sigma W_{c s, T i} \\
& W_{c s, s l}=\left(W_{c s, s m}+W_{\text {loss }}\right) / f_{t c}
\end{aligned}
$$

The corresponding settled solids (s-sol) weight is calculated from the c-sol weight by dividing by the $r_{c / s}$ ratio, as shown in Eq (2-4).

$$
W_{s s, s t}=W_{c s, s t} / r_{c / s}
$$

A spreadsheet relating the parameters to the weights required has been developed to estimate the weights for any combination of parameter values. Table 2-1 illustrates the weights of solids required for some parameter values. The column labels (Low, Med, and High) reflect the magnitude of the losses considered. The comparison of the three left-hand columns with the next three columns shows the range in values resulting from using $f_{i}$ values of 0.95 (left-hand), or 0.85 (for $i=1$ to 3 ). This range of values is 
HNF-5665, Rev. 0

appropriate for tanks with low ionic strength where 5 to 15 wt\% of the solids are composed of soluble sodium salts. Contact Process Chemistry for better estimates for specific tanks.

Table 2-1. Weights of Solids Illustrating Effects of Different Parameter Values for Tanks with Low Ionic Strength.

\begin{tabular}{||l|r|r|r|r|r|r|r|r||}
\hline & \multicolumn{1}{|c|}{ Low } & \multicolumn{1}{|c|}{ Med } & High & Low & Med & High & Med & Med \\
\hline & \multicolumn{1}{|c|}{$f_{i}{ }^{1}=0.95$} & \multicolumn{5}{|c|}{$f_{i}{ }^{1}=0.85$} \\
\hline$W_{\text {lab }}, g$ & 9 & 11 & 14 & 9 & 11 & 14 & 11 & 11 \\
\hline$W_{\text {loss }}, g$ & 0 & 0.5 & 1 & 0 & 0.5 & 1 & 0.5 & 0.5 \\
\hline$f_{t c}$ & 0.93 & 0.80 & 0.62 & 0.93 & 0.80 & 0.62 & 0.80 & 0.80 \\
\hline$f_{t v}$ & 0.98 & 0.94 & 0.90 & 0.98 & 0.94 & 0.90 & 0.94 & 0.94 \\
\hline$W_{c s, s m}, g$ & 41 & 64 & 112 & 45 & 69 & 122 & 69 & 69 \\
\hline$W_{c s, s l}, g$ & 44 & 80 & 182 & 48 & 87 & 198 & 87 & 87 \\
\hline$r_{c / s}$ & 0.8 & 0.7 & 0.6 & 0.8 & 0.7 & 0.6 & 0.6 & 0.5 \\
\hline$W_{s s, s l}, g$ & 55 & 114 & 303 & 60 & 125 & 330 & 145 & 174 \\
\hline
\end{tabular}

${ }^{1}$ Same $f_{i}$ value used for $i=1$ to 3 , together with $f_{4}=1$.

The parameter values shown are typical for recoveries. For example, $f_{\text {tc }}$ values of $0.62,0.88$, and 0.93 were observed for three tanks for transferring solids out of centrifuge cones. It seems likely that tools and techniques can be developed to improve the transfer fraction from the cones to something like 0.8 to 0.95 (with a small amount of material lost on the tool).

The estimates for $W_{\text {lab }}$ were based on the experience that sample vials with 14 to $16 \mathrm{~g}$ always had sufficient material for the number of analyses requested in this plan. Vials with 9 to $12 \mathrm{~g}$ were sufficient for most cases, but unusually large subsampling losses sometimes depleted the sample before all analyses were completed. Samples as small as $5 \mathrm{~g}$ will give results for two or three digests. Furthermore, the number of required digests can be reduced by doing the ICP analysis on the fusion digest (required for radiochemical analyses) rather than on an acid digest, if $W_{\text {lab }}$ is small.

Additional solids are required when the solids contain a significant amount of soluble salts (with $f_{i}$ less than 0.85 ). For these tanks, use information about the composition of the solids in the tanks to estimate $f_{j}$. Note that $f_{4}$ is equal to one, as Test 4 uses undiluted material. A general guideline for estimating the $f_{i}$ factors is that sodium salts are normally soluble (except for sodium oxalate) in the inhibited water diluent, while the metal oxides and hydroxides [e.g., $\mathrm{Al}(\mathrm{OH})_{3}$ and $\left.\mathrm{Cr}(\mathrm{OH})_{3}\right]$ are insoluble. Furthermore, the different sodium salts have different solubilities, with carbonate, phosphate, and sulfate being less soluble than aluminate, nitrite, and nitrate. Thus, tanks that have a significant fraction of the solids 


$$
\text { HNF-5665, Rev. } 0
$$

composed of sodium salts (other than oxalate) will have $f_{i}$ factors significantly smaller than one.

The solubility of the sodium salts normally decreases as the ionic strength increases. Furthermore, $\mathrm{Na}^{+}$is normally the dominant positive ion, so that tanks with low ionic strength have low $\mathrm{Na}^{+}$concentrations. As a result, sodium salts will tend to remain in solution (sodium oxalate being the main exception) for tanks with low ionic strength. However, some sodium salts (e.g., $\mathrm{Na}_{7} \mathrm{~F}\left(\mathrm{PO}_{4}\right)_{2}, \mathrm{Na}_{3} \mathrm{PO}_{4}$, and $\left.\mathrm{Na}_{2} \mathrm{SO}_{4}\right)$ are relatively insoluble; such salts may precipitate at relatively low $\mathrm{Na}^{4}$ concentrations. However, in tanks with high ionic strengths, the high $\mathrm{Na}^{+}$concentrations will often cause precipitation of sodium salts (so that these tanks are likely to have salts that dissolve when diluted).

When the liquid has a low sodium concentration, the soluble sodium salts are likely to be in solution. Using tank 101-AZ as an example, grab samples of liquid have a sodium molarity of $4.1 \mathrm{M}$ [see Revision $0-C$ (Templeton 1999a) of the tank characterization report (Hodgson 1995)]. The analyses of sludge from core samples indicate the dry solids in tank 101-AZ to be primarily oxides of iron, aluminum, and zirconium, with minor contributions from oxides of $\mathrm{Si}, \mathrm{Cd}$, and $\mathrm{U}$, as well as some sodium oxalate. The analyses indicate that the contribution of any water-soluble sodium salts (other than oxalate) is a small percentage of the weight $(<15 \mathrm{wt} \%)$ of the other solids. Thus, $f_{j}$ is estimated to be greater than 0.85 for the three dilution tests (Tests 1 - 3). As discussed above, this is likely to be true for other tanks with low sodium concentrations.

When the 1 iquid has a large sodium concentration, many sodium salts may be present as solids. For these tanks, estimate the wt\% of the different sodium salts (e.g., Person 1999a). As a conservative first approximation, assume all the non-oxalate sodium salts are soluble. Then, the weight fraction that remains undissolved is equal the sum of the insoluble hydroxides and oxides and sodium oxalate divided by the total wt\% of all dry solids. The first approximation can also use this same factor for Tests 1 through 3 (more realistically, $f_{1}$ would be somewhat larger).

In summary, the $f_{i}$ factors can be estimated as 0.85 (or larger) for tanks with low ionic strength where the solids contain relatively small amounts of non-oxalate sodium salts, but the $f_{i}$ factors must be estimated for tanks with high ionic strength. As an example calculation, consider the requirements when medium losses are assumed and the ionic strength is low. For this example, the "Med" columns of Table 2-1 show that a range of 0.95 to 0.85 for $f_{1}$ to $f_{3}$ requires having 64 to $69 \mathrm{~g}$ of $\mathrm{c}-\mathrm{sol}$ after the solids are separated. This corresponds to having 80 to $87 \mathrm{~g}$ of c-sol in the slurry. In addition, the amount of settled solids required is larger than the amount of c-sol by the $1 / r_{c / s}$ factor, which has an approximate range from 1.1 to 2 .

The two right-hand columns in Table 2-1 illustrate the effects of different $r_{c / s}$ ratios for the medium losses. These two columns show different amounts of $s-s 01$ required when the $r_{\mathrm{c} / \mathrm{s}}$ ratio has the lower values of 0.6 and 0.5 (compared with the value of 0.7 in the "Med" column that also has 0.85 for the $f_{i}$ value). Thus the amount of s-sol slurry required is 125,145 , and $174 \mathrm{~g}$ as the value of $r_{c / s}$ decreases from 0.7 , to 0.6 , to 0.5 , respectively. 
HNF-5665, Rev. 0

The amount of solids required thus depends on several assumptions. As a reasonable first guess, a minimum weight of equilibrated settled solids is 120 to $170 \mathrm{~g}$ for tanks with low ionic strength. However, larger amounts are required when larger losses are considered.

\subsection{DESCRIPTION OF TEST}

Sample preparation and all of the testing will be done in hotcells at the 222-S Laboratory. The starting material will be prepared in the large hotcells in room $11 \mathrm{~A}$ of the 222-S Laboratory. It is currently planned that the other activities described in this test plan (except for analysis) will be performed in the 11A5 hotcell. Other portions of the 11A hotcells may be used, as needed or as space is available.

The starting material will be prepared by the llA personnel. Sufficient material (see Section 2 for estimation of solids required) will be submitted to Process Chemistry personnel for the Solids Solubility Screening Tests.

\subsection{Observations on Starting Material}

3.1.1. Record the weights of samples received.

Note: Maintain a log of bottle weights for each transfer; perform a material balance to account for all material sampled.

Note: If the starting material is a slurry already, record the vol\% settled solids, shake the mixture, and go to Section 3.1.5.

3.1.2. Tare and label four tall jars of the appropriate size to contain the mixed slurry composites.

3.1.3. Add solids composite and liquid composite by mass to each jar. Add solids composite and liquid composite in the mass ratio calculated to match the mass ratio for the core sample. Use the estimated $f_{i}$ factors (Section 2.2) to prepare the amount of solids composite for each Test.

3.1.4. Mix for 24 hrs.

3.1.4a. Shake vigorously at hourly (approximately) intervals during working hours. It is expected that the shaking will begin on one day with several shakings and end 24 hours later after some additional shakings during working hours.

3.1.5. Settle for at least $48 \mathrm{hrs}$.

3.1.5a. Record hotce 11 ambient temperature during the settling. Record observations of solids properties and gelation; 
HNF-5665, Rev. 0

record any visual observation of floating layers (organic or solids) and any indication of gas generation.

3.1.5b. Measure the heights of settled solids at times during the period. Measure the total height of solids and liquid at least once.

3.1.5c. If the liquid is too turbid to determine the top of the solids, allow the material to settle longer (wait at least 24 hrs more).

3.1.6. Measure and record the volume and mass of each sample slurry.

\subsection{Centrifuged Solids (C-Sol) Preparation}

The next steps separate the solids and liquids from the slurry samples for the four tests. This is done by centrifugation, al though clear liquid may be decanted from the settled solids when there is a clear liquid layer.

3.2.1. Separate the liquids and solids by centrifugation (use approximately $300 \mathrm{G}$ force for $30 \mathrm{~min}$ ), observing and documenting the degree of separation (completion of centrifugation determined by technical judgment of chemist).

Note: Dilution of sample minimized during all transfers by rinsing containers with the separated liquid fraction.

3.2.2. Record the weights of separated liquid and of c-sol.

3.2.3. Record the volumes and the calculated densities of the separated liquid and of c-sol.

3.2.4. Record visual observations, including (1) quality of separation, (2) presence of floating layers (organics or solids) and (3) any indications of gas generation within sample.

3.2.5. Use the c-sol to form the four test mixtures, following directions in Section 3.3.1. Save liquid that was equilibrated with the c-sol used to prepare the Test 4 samples. The liquid will be used for analysis in Section 3.3.6. There are no other needs for the liquids in this test plan.

3.2.6. Record the weight of c-sol jar after removing material for Step 3.2.5. 
HNF-5665, Rev. 0

\subsection{Solubility Screening Tests}

The experiment listed below will indicate the effects of dilution on the solids. These data will be used in assessing the impact of solids on meeting Privatization Contract envelope specifications and will provide input to aid in designing solids dissolution testing for waste retrieval. An additional objective is to use a standardized solubility testing procedure to allow waste-to-waste comparisons to be made easily. Additional analyses of the solids may be requested by the chemist in consultation with the Tank Coordinator.

3.3.1. Tare and label containers of appropriate size to hold the diluted test mixtures. When the diluted volume expected for the test is $45 \mathrm{~mL}$ or less, use one $50 \mathrm{~mL}$ centrifuge cone as the container. Use one vial or tall jar of the appropriate volume for diluted volumes larger than $45 \mathrm{~mL}$. The container size should be large enough to accommodate shaking the diluted material.

3.3.2. Add $\mathrm{c}-\mathrm{sol}$ by mass to the containers.

3.3.2a. Test 1: 100 parts (by mass) c-sol plus 25 parts (by mass) diluent (inhibited water).

3.3.2b. Test 2: 100 parts (by mass) c-sol plus 75 parts (by mass) diluent (inhibited water).

3.3.2c. Test 3: 100 parts (by mass) c-sol plus 100 parts diluent (inhibited water).

3.3.2d. Test 4: 100 parts (by mass) c-sol with no dilution.

Note: Inhibited water is $0.01 \mathrm{M} \mathrm{NaOH}$ and $0.01 \mathrm{M} \mathrm{NaNO}_{2}$ (sodium nitrite).

3.3.3. Mix for $24 \mathrm{hrs}$.

3.3.3a. Shake vigorously at hourly (approximately) intervals during working hours. It is expected that the shaking will begin on one day with several shakings and end 24 hours later after some additional shakes during working hours.

3.3.4. Settle for at least 72 hrs.

3.3.4a. Record hotcell ambient temperature at the beginning, end, and at times during the settling. Record observations of solids properties and gelation; record any visual observation of a separate organic layer.

3.3.4b. Measure the heights of settled solids at several times during the period (e.g., at 1, 2, 4, 20, 24, 28, 48, and 72 hrs). The heights may be recorded in $\mathrm{mL}$, after not ing the $\mathrm{cm} / \mathrm{mL}$ ratio. Record the total height at least once.

3.3.5. Separate the solids and liquids. 
HNF-5665, Rev. 0

3.3.5a. Decant the 1iquid fraction from each test with the goal of having the remaining material fit in one $50 \mathrm{~mL}$ centrifuge cone (measure the volume and mass of the liquid removed). Transfer the decanted liquid into clean (tared and labeled) containers (e.g., $50 \mathrm{~mL}$ cones). Leave enough liquid with the solids to allow efficient transfer of the solids.

3.3.5b. Collect all solids into one tared and labeled centrifuge cone. Centrifuge the cone (use approximately $300 \mathrm{G}$ force for about $30 \mathrm{~min}$ ), observing and documenting the degree of separation (completion of centrifugation determined by technical judgment of chemist). Record any visual observation of a separate organic layer. Decant the liquid into the liquid container (see step 3.3.5a). If necessary to collect solids from different cones, use some supernate to slurry the solids into one cone and recentrifuge that cone, decanting the liquid into the liquid container. Weigh the cone before and after any supernate addition.

3.3.5c. Measure and record the volumes and masses (to determine the densities) of the solids and liquids.

3.3.6. Submit an aliquot of the separated liquids (mix first) of each test mixture for the analyses listed in steps 3.3.6a and 3.3.6b. Prepare two vials with 10 to $14 \mathrm{~mL}$ in each vial (only one vial if less than $14 \mathrm{~mL}$ total volume available). If volume is less than $14 \mathrm{~mL}$ for Test 4 , add the separated liquid saved from this sample in Step 3.2.5 to give a total volume of 20 to $28 \mathrm{~mL}$ (half in each vial). If volume is less than $9 \mathrm{~mL}$ for Tests 1 through 3 , add a known weight of deionized water to make the diluted volume $12 \mathrm{~mL}$ or more. Record vol\% dilution.

3.3.6a. Analyze sample for $\mathrm{Na}, \mathrm{A} 1_{6 \mathrm{O}} \mathrm{Cr}, \underset{154}{\mathrm{P}}, \mathrm{S}, \underset{155}{\mathrm{Si}}, \mathrm{OH}, \mathrm{NO2}, \mathrm{NO3}, \mathrm{Cl}$, F, TIC, TOC, ${ }^{90} \mathrm{Sr},{ }^{137} \mathrm{Cs},{ }^{60} \mathrm{Co},{ }^{154} \mathrm{Eu},{ }^{155} \mathrm{Eu}$, and total alpha using the methods and QC parameters out 7 ined in Table 7.1 of the DQO (Patello 1999). Report all analytical results recovered for opportunistic analytes (Kristofzski 1996) to the extent that no additional standards or reruns are required.

3.3.6b. Analyze sample for wt\% solids (gravimetric by heating to constant weight at $105{ }^{\circ} \mathrm{C}$ ). If the amount of liquid in the vial(s) in Step 3.3 .6 is less than $20 \mathrm{~mL}$, use approximately $1 \mathrm{~g}$ for the sample (and duplicate) when determining the wt\% solids; otherwise, larger samples may be used.

Note: The specified sample sizes in Steps $3.3 .6 \mathrm{~b}$ and $3.3 .7 \mathrm{~b}$ are from the DQO specifications (Section 7.3.4 of Patello 1999) that use sample sizes of 5 to $10 \mathrm{~g}$ and allow smaller sample sizes due to sample quantity limitations.

3.3.7. Submit an aliquot of solids (mix well first) of each test mixture for the analyses listed in steps $3.3 .7 \mathrm{a}$ and $3.3 .7 \mathrm{~b}$. If there is 
HNF-5665, Rev. 0

only a small amount of solids after any dilution test (e.g., less than $2 \mathrm{~g}$ ), do step 3.3 .8 in place of this step.

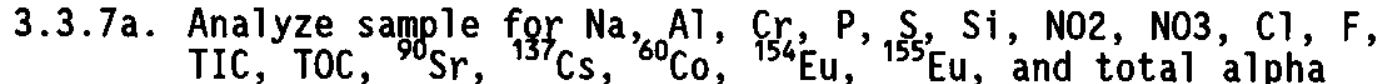
using the methods and QC parameters outlined in Table 7.2 of the DQO (Patello 1999). Use a water digest for the IC analytes (anions) and for TOC, direct solid samples for TIC and $T O C$, and a fusion digest for the radiochemical analytes (including total alpha). If the sample size is greater than $9 \mathrm{~g}$, use an acid digest for the ICP analytes (cations). If the sample size is less than $9 \mathrm{~g}$, conserve sample by doing the ICP analysis on the fusion digest already performed. Report all analytical results recovered for opportunistic analytes (Kristofzski 1996) to the extent that no additional standards or reruns are required.

3.3.7b. Analyze sample for wt\% solids (gravimetric by heating to constant weight at $105{ }^{\circ} \mathrm{C}$ ). If the amount of solids in the vial in Step 3.3.7 is less than $20 \mathrm{~g}$, use approximately $1 \mathrm{~g}$ for the sample (and duplicate) when determining the wt\% solids; otherwise, larger samples may be used.

3.3.8. At the discretion of the chemist in charge, in consultation with the tank coordinator, other tests may be performed. This can help identify the solids, especially if the amount of solids remaining is insufficient for the full suite of tests. Possible other tests are x-ray diffractometry, polarized light microscopy (PLM), and scanning electron microscopy/energy dispersive $x-r a y$ spectroscopy.

\subsection{DATA INTERPRETATION}

\subsection{Chemical Data}

Chemical analyses of centrifuged liquid and solid phases will be used to develop knowledge of the chemical properties of the solid phase. The analyses of the material from the four screening tests (Section 3.3) will be used together with any analyses of the liquid fraction and the solid fraction of the riser composite available from samples prepared by $11 \mathrm{~A}$ personnel according to the SAP for the tank. With analyses of both the liquid and the c-sol samples, it will be possible to calculate the contribution of the interstitial liquid to the centrifuged solids and to estimate a composition of the true solid phase at each dilution. Knowledge of the solid phases present as a function of dilution ratio should provide the information needed to explain the physical (solubility) data.

As a first approximation, the assumption will be made that all of the water in the centrifuged solids can be attributed to interstitial liquid. If the calculations and/or PLM results suggest that the true solid phase contains some salts that are highly hydrated [e.g. $\left.\mathrm{Na}_{7} \mathrm{~F}\left(\mathrm{PO}_{4}\right)_{2} \cdot 19 \mathrm{H}_{2} \mathrm{O}\right]$, then an iterative 
HNF-5665, Rev. 0

calculation may be required to distribute the water in the centrifuged solids between the true solid phase and the interstitial liquid phase.

The list of analytes from the ICP and IC analyses that will be reported will be longer than those requested (per "opportunistic" analysis memo [Kristofzski 1996]).

\subsection{Quality Assurance}

Based on the requirements in "Review and Approval of Documents", HNF-PRO-233, this test plan is assigned Approval Designator E. Approval signatures are required from the author, immediate manager, Environmental Compliance reviewer, and a representative of the receiving organization.

Analyses that do not meet the $Q C$ requirements of the $D Q 0$ (Tables 7.1 and 7.2 of Patello 1999) will either be rerun or reported as not meeting the requirements in the final report. Analytical QA will meet the requirements of the 222-S Lab QA plan (Markel 1999) as modified by the DQO (Patello 1999) and the SAP for the tank.

The solubility screening tests will follow the "Process Chemistry \& Statistics Quality Assurance Plan", WHC-SD-CP-QAPP-018, Rev. 0 (Meznarich 1996). The instructions will be recorded in a controlled laboratory notebook, showing observations and data recorded as the work is done. Example data sheets are shown in Appendix A. Minor changes to the work (as determined by the chemist in charge) will be noted in the laboratory notebook and in the test report. Substantive changes to the work will be reviewed by the author, immediate manager, and the customer. Changes that require reviews by

Radiological Control or Environmental Compliance or other entities will have those additional reviews before the changes are implemented.

\subsection{SAFETY}

All of the safety requirements that apply to this test plan are described in "Development of Instrumentation, Methods and Performance of Process Testing", Hanford Analytical Services Laboratory Operating Procedure L0-140-100, and in the WMH-310 Manual "Hanford Analytical Services Laboratory Operations Administration"), Section 4.3, "222-S Laboratory Safety," Section 4.5, "Chemical Hygiene Plan," and Section 1.9, "Laboratory Test Planning."

The work described in this test plan will all be done inside a hotcell. Execution of this program will not involve any hazards beyond the usual laboratory activities. Standard laboratory safety practices will apply. 


\subsection{WASTE HANDLING}

Two waste streams are expected to be generated from this test program. Stream \#1 is the used and left-over tank waste material. This material consists primarily of liquid (containing less than 5 vol\% solids). There may be a small amount of solids also. The total amount of this waste stream is expected to be less than $1 \mathrm{~kg}$. This waste will be discarded to the 219-S Building tanks via a hotcell drain, per procedure L0-100-107, "Cubicle Housekeeping, Waste Disposal, and Management". This waste may be diluted with inhibited water, as noted on the Waste Stream Fact Sheet in Appendix C.

Stream \#2 is the solid hotcell waste consisting of used centrifuge cones, used sample vials, used plastic syringes, etc. This waste will be rinsed with water, removed from the 11A5 hotcell, loaded into waste cans, and disposed of by IlA personnel according to L0-100-151, "Segregate and Manage Solid Laboratory Wastes".

If the tank under study is found to be above regulatory concern for PCBs, all waste streams will be managed and disposed of according to L0-100114, "Management of Polychlorinated Biphenyl (PCB) at the 222-S Laboratory Complex".

Other than the waste streams described here, there will be no accumulating of hazardous waste. The Waste Compatibility Review is attached as Appendix B. The Waste Stream Fact Sheet (listing the components of the diluent added to the waste) is attached as Appendix $C$.

\subsection{SCHEDULE AND DELIVERABLES}

This test plan should be issued by February 16, 2000. The schedule for each tank will depend on the availability of Process Chemistry personnel and on the schedule for preparation of the sample material.

A complete report of the test results will be issued by Process Chemistry in the form of an internal memo to 222-S Laboratory. Informal interim status reports will be given to the customer (via cc:mail or teleconference) at the customer's request. Other requirements may be specified in the SAP. For example, an electronic version of the report and associated data spreadsheets can be provided to the customer, and the 222-S Laboratory can issue a Format IV report that includes Process Chemistry's report. 
HNF-5665, Rev. 0

\subsection{REFERENCES}

Hodgson, K. M. (1995), Tank Characterization Report for Double-Shell Tank 241-AZ-101, WHC-SD-WM-ER-410, Rev. 0, West inghouse Hanford Company, Richland, Washington.

Kristofzski, J. G. (1996), Directions for Opportunistic Analyses, memo 75310-96-168 to J. H. Baldwin, et. al., September 11, 1996, Westinghouse Hanford Company, Richland, Washington

Marke1, L. P., and 222-S Laboratory Technical Teams (1999), 222-S Laboratory Quality Assurance Plan, HNF-SD-CP-QAPP-016, Rev. 3C, Waste Management Federal Services of Hanford, Inc. for Fluor Daniel Hanford, Inc., Richland, Washington.

Meznarich, H. K. (1996), Process Chemistry \& Statistics Quality Assurance P7an, WHC-SD-CP-QAPP-018, Rev. 0, Westinghouse Hanford Company, Richland, Washington.

Pate110, G. K., M. J. Truex, and K. D. Wiemers (1999), Low Activity Waste and High-Level Waste Feed Processing Data Quality Objectives, PNNL-12163, Rev. 0, Pacific Northwest National Laboratory, Richland, Washington.

Person, J. C. (1999a), "Solubility Screening Tests for Tank 241-AW-101," Memo 82100-99-003 to R. A. Esch, February 1, 1999, Numatec Hanford Corporation, Richland, Washington, used as Attachment 2 in R. A. Esch, Report HNF-1653, Rev. 0, 1999, Waste Management Hanford Corporation, Richland, Washington.

Person, J. C. (1999b), Test Plan for Tank 241-AZ-102 Solubility Screening Tests, HNF-4751, Rev. 0, Numatec Hanford Corporation, Richland, Washington.

Person, J. C. (1999C), Test Plan for Tank 241-AZ-101 Solubility Screening Tests, HNF-4752, Rev. 0, Numatec Hanford Corporation, Richland, Washington.

Rasmussen, J. H. E. (1999), Tank 241-AZ-102 Privatization Push Mode Core Sampling and Analysis Plan, HNF-4577, Rev. 3A, Lockheed Martin Hanford Corporation, Richland, Washington.

Templeton, A. M. (1999a), Tank Characterization Report for Double-Shell Tank 241-AZ-101, WHC-SD-WM-ER-410, Rev. O-C, Lockheed Mart in Hanford Corporation, Richland, Washington.

Templeton, A. M. (1999b), Tank 241-AZ-101 Privatization Push Mode Core Sampling and Analysis Plan, HNF-4738, Rev. 0-A, Lockheed Mart in Hanford Corporation, Richland, Washington. 
HNF-5665, Rev. 0

APPENDIX A: EXAMPLE DATA SHEETS

Preparation of Slurry Composite Sample.

Date:

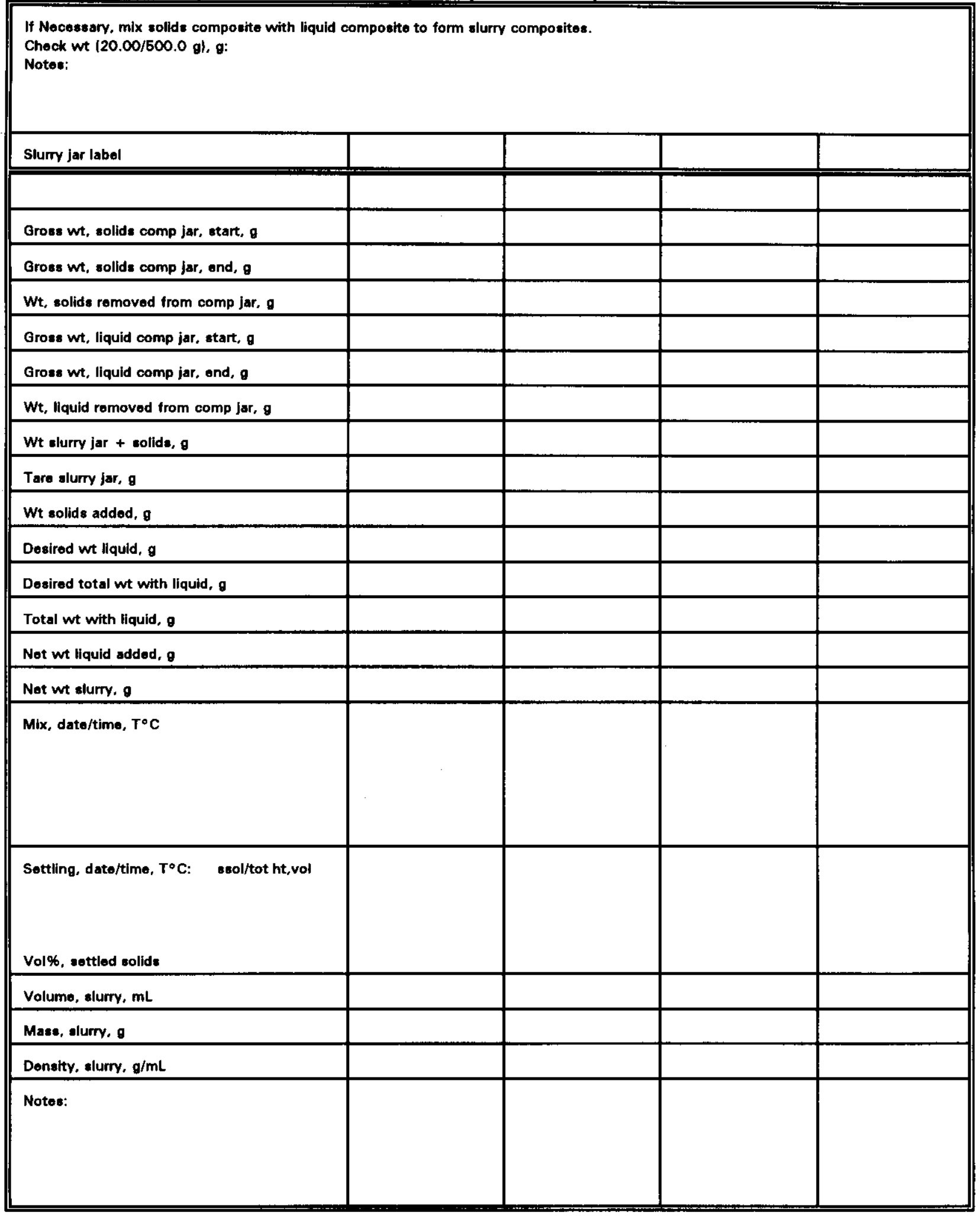


HNF-5665, Rev. 0

Solids/Liquid Separation of Composite Sample. Date:

\begin{tabular}{|c|c|c|c|c|}
\hline Sample & & & & \\
\hline Groses wt, sample jar, $g$ & & \multirow{2}{*}{\multicolumn{2}{|c|}{ Check wt $(20.00 / 500.0$ gl, g: }} & \\
\hline Tare wt, somple jar, $g$ & & & & \\
\hline Not samplo wt, $g$ & & & \multirow[t]{10}{*}{ Notes: } & \\
\hline Date/Time & & & & \\
\hline Tomperature, ${ }^{\circ} \mathrm{C}$ & & & & \\
\hline Total sample hoight, $\mathrm{cm}$ & & & & \\
\hline Settiod solids hoight, $\mathrm{cm}$ & & & & \\
\hline Settled solide vol\% & & & & \\
\hline We after decant liquid, & & & & \\
\hline Wt liquid romoved, samp & & & & \\
\hline Wt ompty sample jar, $\theta$ & & & & \\
\hline Wt residue (and tare erre & & & & \\
\hline Volume liquid decanted & $=\mathrm{mL}$ & To container & Mass of liq & \multirow[t]{4}{*}{ SpG $=$} \\
\hline \multicolumn{4}{|c|}{ Wt decanted liquid + taro, $g$} & \\
\hline \multicolumn{4}{|c|}{ Tare wt, container for decanted liq } & \\
\hline \multicolumn{4}{|c|}{ Wt liq, g (added to container, mass of liq) } & \\
\hline \multicolumn{5}{|l|}{ Solide cone } \\
\hline Grose $w t, g$ & & & \multirow[t]{16}{*}{ Notes: } & \\
\hline \multicolumn{3}{|l|}{ Tare wt, $g$} & & \\
\hline \multicolumn{3}{|c|}{ Wt of solids/liquid in cone, $g$} & & \\
\hline \multicolumn{3}{|l|}{ Total volume in cone, $\mathrm{mL}$} & & \\
\hline \multicolumn{3}{|c|}{ Cone wt after c-liquid decant, $g$} & & \\
\hline \multicolumn{3}{|l|}{ Wt of c-liquid, $g$} & & \\
\hline \multicolumn{3}{|c|}{ Wt of contrifuged solids, g } & & \\
\hline \multicolumn{3}{|c|}{ Volume of centrifuged solids, $\mathrm{mL}$} & & \\
\hline \multicolumn{3}{|c|}{ Denaity of centrifuged solids, $\mathrm{g} / \mathrm{mL}$} & & \\
\hline \multicolumn{3}{|c|}{ Volume, c-liquid decanted, $\mathrm{mL}$} & & \\
\hline \multicolumn{3}{|c|}{ Density of centrifugod liquid, $\mathrm{g} / \mathrm{mL}$} & & \\
\hline \multicolumn{3}{|l|}{ Total volume liquid, $\mathrm{mL}$} & & \\
\hline \multicolumn{3}{|l|}{ Total wt liquid, $g$} & & \\
\hline \multicolumn{3}{|c|}{ Density of total liquid, $\mathrm{g} / \mathrm{mL}$} & & \\
\hline \multicolumn{3}{|l|}{ Wt $\%$ centrifuged solld } & & \\
\hline Vol\% centrifuged solids & & & & \\
\hline
\end{tabular}


HNF-5665, Rev. 0

Solubility Screening Test: Prepare Mixture, Dilute, Settle. Date:

Prepare test mixture using c-sol plus diluent.

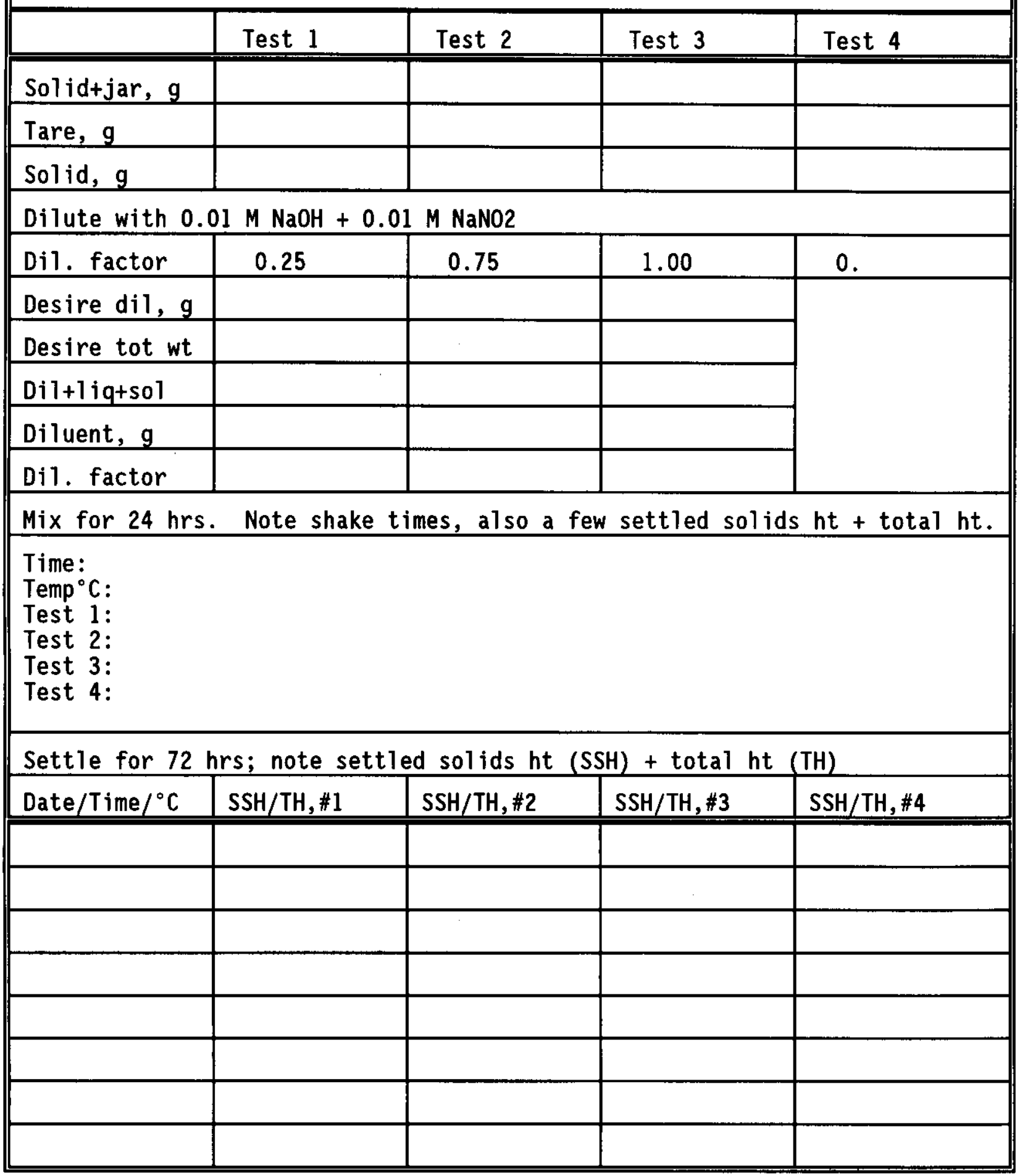


HNF-5665, Rev. 0

Solubility Screening Test: Solid/Liquid Properties. Date:

\begin{tabular}{|c|c|c|c|c|}
\hline \multicolumn{5}{|c|}{ Properties of solids after dilution. } \\
\hline & Tost 1 & Tost 2 & Tost 3 & Tost 4 \\
\hline \multicolumn{5}{|c|}{$W t$ liq + sol + jar, g } \\
\hline \multicolumn{5}{|c|}{ Tare test jar, $g$} \\
\hline \multicolumn{5}{|c|}{ Wt liq + sol, g } \\
\hline \multicolumn{5}{|c|}{ Wt test jar + resid, $g$} \\
\hline \multicolumn{5}{|c|}{ Vol\%, set sol } \\
\hline \multicolumn{5}{|l|}{ Cone Label } \\
\hline \multicolumn{5}{|c|}{ Liq vol cone, $\mathrm{mL}$} \\
\hline \multicolumn{5}{|c|}{ Wt liq + cone, $g$} \\
\hline \multicolumn{5}{|c|}{ Tare cone, $g$} \\
\hline \multicolumn{5}{|c|}{ We liq in cono, $g$} \\
\hline \multicolumn{5}{|c|}{ Spg liq in cone } \\
\hline \multicolumn{5}{|c|}{ Empty cono liquid into "-L" jar, weigh. Decant any additional liquid to " $L$ " jar -- ond with liquid + solids in cone. } \\
\hline \multicolumn{5}{|c|}{ Wt liq $+-L$ jar, $g$} \\
\hline \multicolumn{5}{|c|}{ Tare wt - L jor, $g$} \\
\hline \multicolumn{5}{|c|}{ Wt liq + decant liq, $g$} \\
\hline \multicolumn{5}{|c|}{ Wt docant liq, $g$} \\
\hline \multicolumn{5}{|c|}{ Vol decant liq, $\mathrm{mL}$} \\
\hline \multicolumn{5}{|c|}{ Vol liq + sol(cono), mL } \\
\hline \multicolumn{5}{|c|}{ Wt liq + sol + cone, g } \\
\hline \multicolumn{5}{|c|}{ Wt solide + cone, g } \\
\hline \multicolumn{5}{|l|}{ Wt c-liq, $\mathfrak{g}$} \\
\hline \multicolumn{5}{|l|}{ Wt c-sol, $g$} \\
\hline \multicolumn{5}{|c|}{ Vol c-єol, mL } \\
\hline \multicolumn{5}{|l|}{ Vol c-liq, mL } \\
\hline \multicolumn{5}{|c|}{ SpG c-liq (final cone) } \\
\hline \multicolumn{5}{|l|}{ SpG c-sol } \\
\hline \multicolumn{5}{|c|}{ Tot vol, liq $+201, \mathrm{~mL}$} \\
\hline \multicolumn{5}{|l|}{ Total wt, $g$} \\
\hline Tot vol liq, $r$ & & & & \\
\hline Tot wt liq, : & & & & \\
\hline Tot liq SpO & & & & \\
\hline Wt\% c-Bol & & & & \\
\hline Vol\% c-sol & & & & \\
\hline
\end{tabular}


HNF-5665, Rev. 0

Solids Solubility Tests, Prepare Samples. Date:

For the cones from the four tests, transfer liquid from cones, transferring 10-14 mL to each of two $15 \mathrm{~mL}$ sample vials. If < $14 \mathrm{~mL}$, use one vial, compute volume from $\mathrm{SpG}$, and dilute with water if volume $<9 \mathrm{~mL}$. Transfer solids from cones into solids sample vial; record wts.

\section{Check Wts:}

\begin{tabular}{|c|c|c|c|c|c|c|}
\hline \multicolumn{7}{|c|}{ Prepare liquid samplos. } \\
\hline & \multicolumn{2}{|r|}{ Tost 1} & \multicolumn{2}{|r|}{ Tout 2} & Tost 3 & Tost 4 \\
\hline \multicolumn{7}{|c|}{ Vial number } \\
\hline \multicolumn{7}{|c|}{ Labcore } \\
\hline \multicolumn{7}{|c|}{ Samp + vial } \\
\hline \multicolumn{7}{|c|}{ Tare vial, $g$} \\
\hline \multicolumn{7}{|c|}{ Wt sample, $\mathbf{g}$} \\
\hline Vol, $\mathrm{mL}$ & Vol $=$ & $\mathrm{SpO}=$ & Vol $=$ & $S p G=$ & $\mathrm{Vol}=\quad \mathrm{SpG}=$ & Vol $=$ \\
\hline \multicolumn{7}{|c|}{$w t s+w a t+v$} \\
\hline \multicolumn{7}{|c|}{ Wt $\mathrm{H} 2 \mathrm{O}$ add } \\
\hline \multicolumn{7}{|c|}{ Vol\% Diln } \\
\hline \multicolumn{7}{|l|}{ Notes } \\
\hline \multicolumn{7}{|c|}{ Prepare solids samples. } \\
\hline & & Tost 1 & & Tost 2 & Test 3 & Teat 4 \\
\hline \multicolumn{7}{|c|}{ Vial number } \\
\hline \multicolumn{7}{|l|}{ Labcore } \\
\hline \multicolumn{7}{|c|}{ Samp + vial } \\
\hline \multicolumn{7}{|c|}{ Tare vial, $\mathbf{g}$} \\
\hline \multicolumn{7}{|c|}{ Wt sample, $g$} \\
\hline Notes & & & & & & \\
\hline
\end{tabular}




\author{
HNF-5665, Rev. 0
}

APPENDIX B: WASTE COMPATIBILITY REVIEW

\title{
COMPATIBILITY REVIEW
}

PROCEDURE NUMBER: $\quad$ HNF-5665, Rev. 0 (Generic Test Plan for Solubility Screening Tests)

CHEMICALS OF CONCERN IN WASTE STREAM

MAXIMUM CONCENTRATION

$\mathrm{NaOH}$ (sodium hydroxide)

$\mathrm{NaNO}_{2}$ (sodium nitrite)

$0.006 \mathrm{M}$

$0.006 M$

COMPATIBILITY HAZARDS, INCLUDING SPECIAL STORAGE REOUIREMENTS, POSSIBLE

REACTIONS, AND RESULTS OF MIXING INCOMPATIBLE WASTE STREAMS

None, as $\mathrm{NaOH}$ and $\mathrm{NaNO}_{2}$ are present within the waste at concentrations much greater than the concentrations added.

\section{RECOMMENDED WASTE STREAMS}

See section 6.0 of Test Plan. Procedure L0-100-107 is followed for waste disposal and management of waste stream \#l (used and left-over tank waste material) in the hotcell. Procedure L0-100-151 is followed for waste disposal and management of waste stream \#2 (solid waste, such as used centrifuge cones, etc.) in the hotcell.

\section{CONTAINER MATERIAL}

glass or plastic

\section{REFERENCE DOCUMENTS USED IN COMPATIBILITY STUDY}

none required

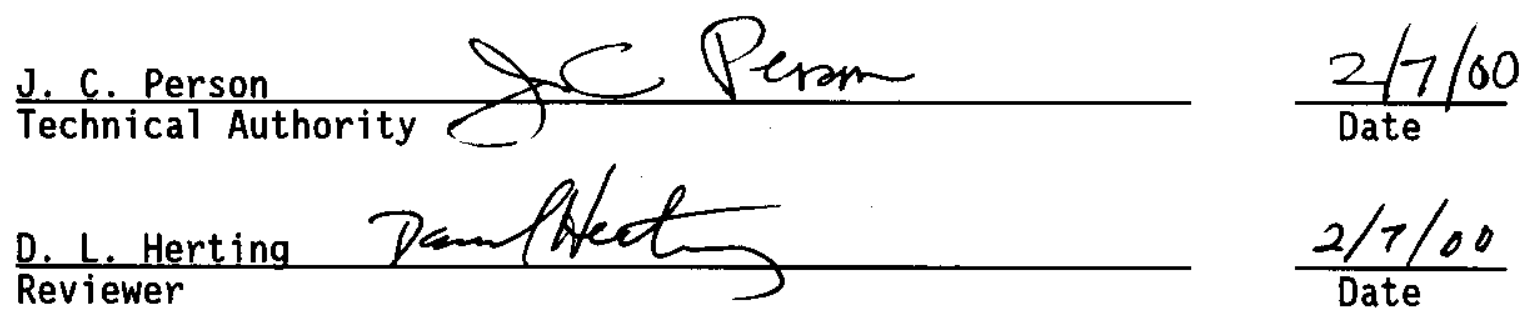


HNF-5665, Rev. 0

APPENDIX C: WASTE STREAM FACT SHEET

\section{2-S LABORATORY \\ DEVELOPMENTAL METHOD WASTE STREAM FACT SHEET}

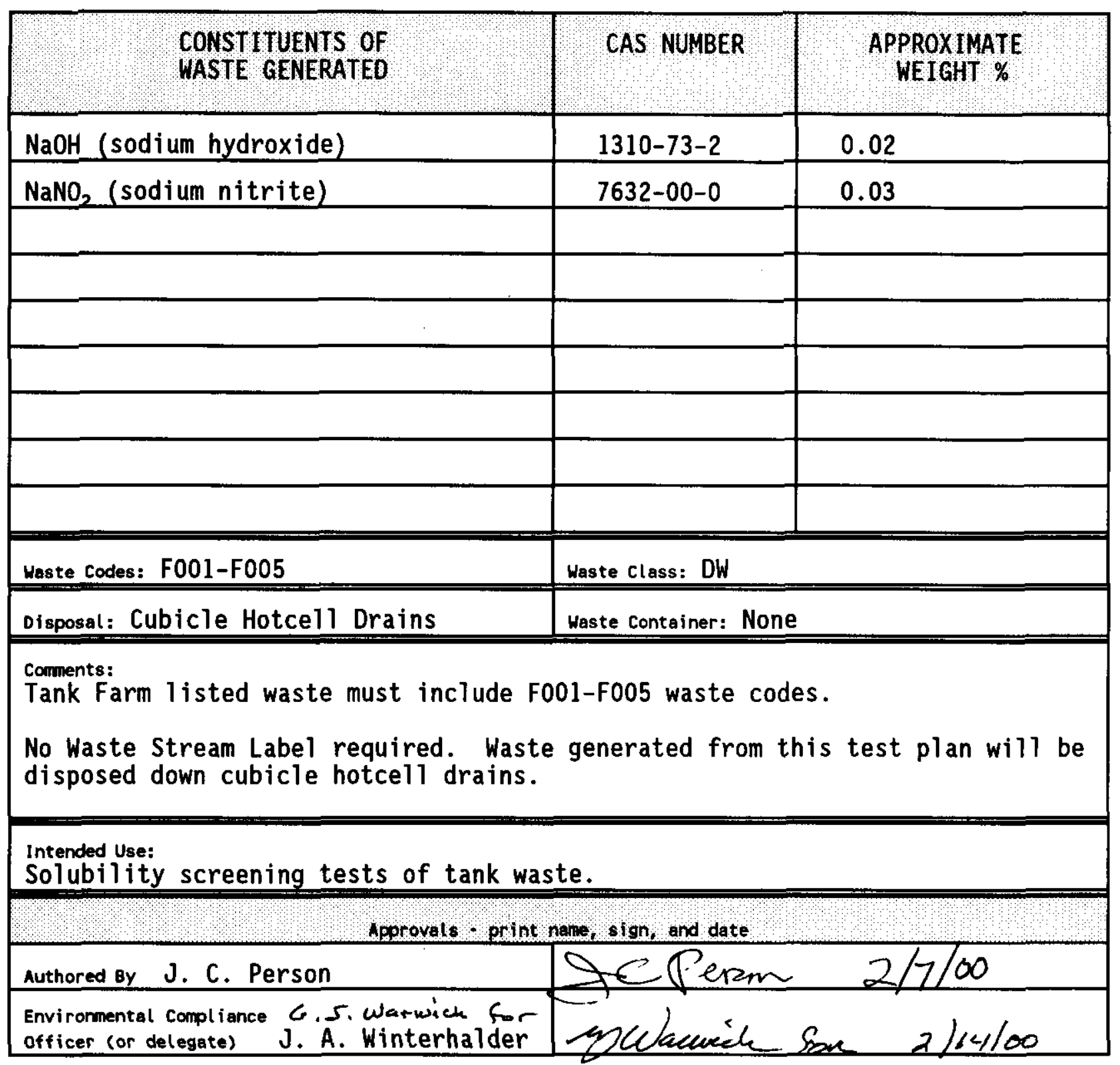

Waste Stream Labeling Requirements: (Waste Stream type, container type, waste codes, and disposal criteria are required.) Waste class is optional. The label is considered to be an example label, but contains the required information for waste stream identification. Other hazardous waste labeling requirements may apply.

\begin{tabular}{|c|c|c|}
\hline Uaste Stream Type & Vaste Stream Number & Page Number \\
\hline Aqueous & 1 of 2 & 1 of 1 \\
\hline
\end{tabular}




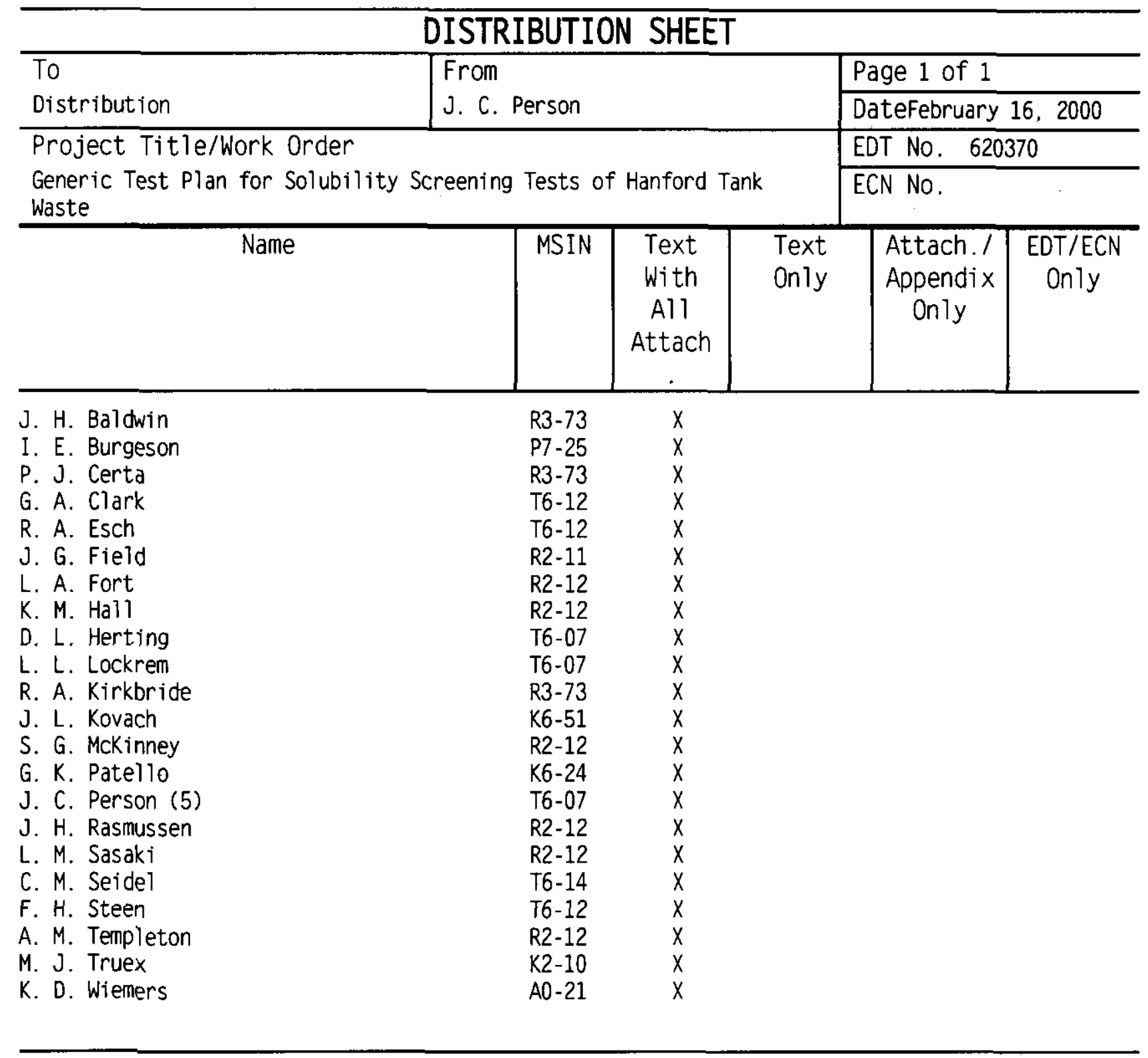

